\title{
Penile fracture with urethral injury: Our experience in a tertiary care hospital
}

\author{
Priyatham Kasaraneni, Prasad Mylarappa, Ramesh Desi Gowda, Sandeep Puvvada, Dheeraj Kasaraneni \\ Department of Urology MS Ramaiah Medical College, Bengaluru, India.
}

\begin{abstract}
Summary Penile fracture is a rare urological emergency that always requires immediate attention. It may be associated with urethral trauma in $9 \%$ to $20 \%$ of cases. We present our experience in treating 12 such cases. This is a prospective observational study extending from January 2000 to December 2016. Each patient with penile fracture underwent a thorough clinical evaluation and received proper treatment. Seventy-five patients with penile fracture, aged 25 to 36 years (mean, 31.5 years) were evaluated in this study. Sexual intercourse was the common mechanism of injury in most of the patients. 12 of the patients had associated urethral injury. All the patients were diagnosed on taking proper history and after clinical examination. All patients were subjected emergency surgical exploration. All the patients underwent minimum of 1 year of follow-up, and were evaluated with local examination, uroflowmetry and Colour Doppler ultrasonography. Penile fracture is associated with urethral injury especially in the presence of suggestive history and physical examination like acute urinary retention, bleeding per urethra. Immediate primary surgical management of both the penile fracture and urethral injury is a safe and effective option with minimal complications.
\end{abstract}

KEY WORDS: Penile fracture; Urethral injury; Corpora; Tunica; Detumescence.

Submitted 4 October 2018; Accepted 15 November 2018

\section{INTRODUCTION}

Penile fracture is defined as the rupture of the tunica albuginea of the corpus cavernosum caused by blunt trauma to the erect penis (1). There might be associated injuries which include partial or complete transection of urethral or spongiosal tissue (2). The tunica albuginea layer is a tough fibroelastic sheath, which envelops the ventral corpus spongiosum and dorsally paired corpora cavernosa (3). Buck's fascia and the deep perineal tissue plane that surrounds both the cavernosa and penile vessels, merges proximally with the deep urogenital region. The characteristic injury patterns associated with penile fractures depend on the integrity of this tissue plane. Upon tunical disruption, cavernosal bleeding can leak into surrounding tissues and remains in the penis by an intact Buck's fascia (4). Penile fracture is mostly associated with sexual intercourse and occurs when the rigid penis slips from the vagina striking the partner's perineum or pubic bone. In Middle East countries, a com- mon cause of penile fracture is self-inflicted injury. The other cause, Taqaandan has been described as an intentional, forceful bending of the erect penile shaft as cultural habit to provide relaxation and release tension (5). With an annual incidence of 0.29-1.36 cases per 100,000 people, some additional etiologies were mentioned in the literature which include impaling a penis in a mattress, slamming the penis in a door, placing an erect penis into tight pants, striking a toilet seat, hitting a bedpost, falling from a tree, and masturbating into a cocktail shaker (6-12). Most likely, the laceration is unilateral though bilateral rupture accounts for 2\% to 10\% of cases. Associated urethral injury is rare, with reported frequencies in $10 \%$ to $38 \%$ (13). Urethral injury may be suspected if there is hematuria and inability to void. The presenting features are relatively consistent and typically straightforward. The simple clinical diagnosis usually renders adjunct imaging unnecessary.

Historically, penile fracture management included mostly conservative, nonsurgical measures. In the 1980s, operative intervention became favorable after several studies demonstrated a decrease in long-term morbidity (14-15). Nowadays, immediate surgical exploration is the standard of care because of its advantages like lesser complications, decreased hospital stays, improved outcomes, and better patient satisfaction. Not many studies were present on case series of penile fracture with urethral injury apart from case reports. This study is based on our experience with 8 cases of penile fracture associated with urethral injury that were treated at a tertiary care hospital.

\section{MATERIALS AND METHOdS}

We did a prospective observational study. Seventy-five cases of penile fracture were presented to the emergency ward from January 2000 to December 2016. Out of them, only 12 had associated urethral injury. Informed written consent was taken from all the patients.

Diagnosis was made on patient's history and clinical examination alone. We didn't subject the patients to any radiological investigation. When clinical diagnosis was in doubt in cases of no urethral injury, we had done ultrasonography of penis to look for tunical tears.

We subjected all cases to emergency surgical exploration (Figures 1-4). Circumferential sub coronal incision was 


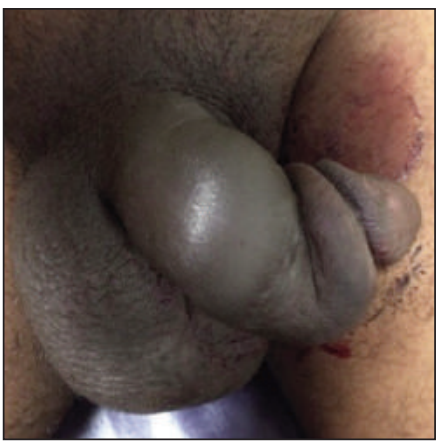

Figure 1.

Penile fracture with blood at meatus and developing hematoma.

Figure 2.

Hematoma in the Buck's fascia at the proximal part.

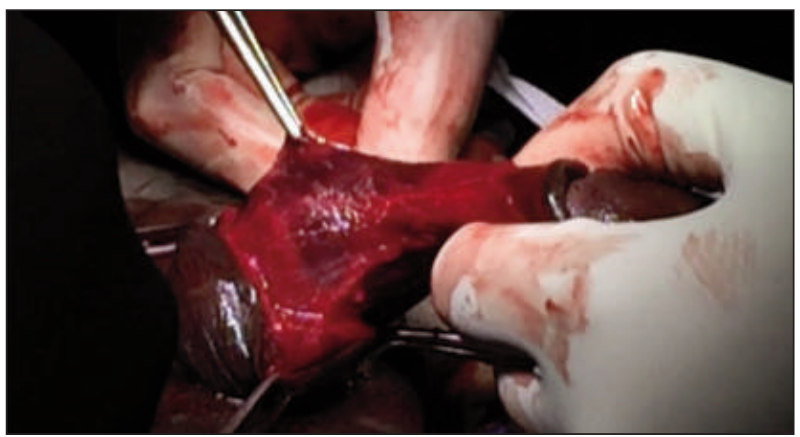

Figure 3.

Intraoperative photo demonstrating bilateral transverse rupture of the corpora and complete urethral transection.

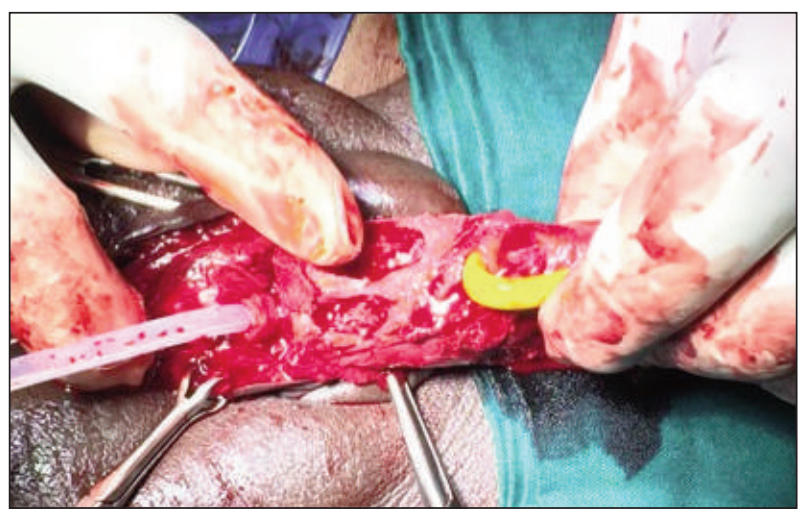

Figure 4.

Photo showing primary reanastomosis of urethra.

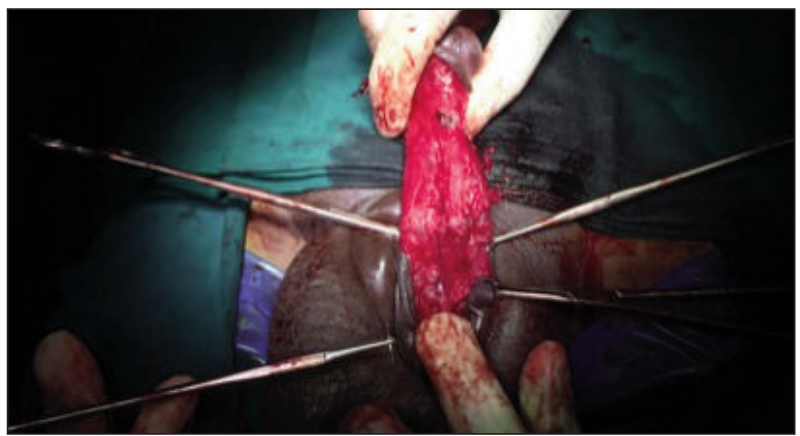

given to deglove the penis for complete evaluation of injuries. Corporal tears were closed with non-absorbable suture (vicryl 3-0). Urethral injuries were looked for and if present, mobilization of urethra done to get length for tension free anastomosis. Urethra was anastomosed after cutting the margins with absorbable suture (4-0 vicryl) for water tight anastomosis. A 16 Fr Foley catheter was used for urinary catheterization. All patients were discharged on the $2^{\text {nd }}$ postoperative day. To prevent painful erections, estradiol $0.05 \mathrm{mg}$ was given for 3 weeks. The urethral catheter was removed after 3 weeks. All the patients were followed up at 3 months and 1 year with clinical examination, uroflowmetry and color Doppler.

\section{RESULTS}

Twelve patients out of 75 patients with penile fracture had associated urethral injury. The following Table 1 shows the demographical values of the study.

We suspected urethral injury clinically on the basis of history in all patients as they had either difficulty voiding, retention of urine or bleeding per urethra and rest of typical features like Aubergine sign, crackling sound were also looked for (Table 2). Retrograde urethrogram was not used in our study. History of sexual intercourse with woman on top position was present in 7 patients whereas 1 patient had history of blunt injury and 2 patients had history of rolling over in the bed. Seven patients heard crackling sound at the time of injury. Eleven patients had bleeding per urethra. Three patients

Table 1.

Demographics of the study.

\begin{tabular}{|lc|}
\hline Parameter & Value \\
\hline Incidence of urethral injury & 12 out of 75 cases (16\%) \\
\hline Mean time from the time of injury & 4.62 hours \\
\hline to the time of presentation to the hospital & 31.5 years \\
\hline Mean age & $25-36$ years \\
\hline Age range & $10(83.33 \%)$ \\
\hline No of urban population affected & $2(16.66 \%)$ \\
\hline No of rural population affected & \\
\hline
\end{tabular}

Table 2.

Clinical findings.

\begin{tabular}{|lc|}
\hline Clinical findings & Incidence \\
\hline History of sexual intercourse with woman on top position & $9(75 \%)$ \\
\hline History of rolling over in the bed & $2(16.66 \%)$ \\
\hline History of blunt injury & $1(12.5 \%)$ \\
\hline History of crackling sound & $7(58.33 \%)$ \\
\hline Bleeding per urethra & $11(91.66 \%)$ \\
\hline Aubergine sign/egg-plant deformity & $12(100 \%)$ \\
\hline
\end{tabular}

Table 3.

Intraoperative findings.

\begin{tabular}{|lc|}
\hline Intra operative findings & Number of cases \\
\hline Partial urethral disruption & $11(91.66 \%)$ \\
\hline Complete urethral disruption & $1(8.33 \%)$ \\
\hline Location of injury - Proximal shaft of penis & $6(50 \%)$ \\
\hline Location of injury - Mid shaft of penis & $2(16.66 \%)$ \\
\hline Location of injury - Distal shaft of penis & $4(33.33 \%)$ \\
\hline
\end{tabular}


weren't able to void from the time of injury. Aubergine sign was present in all the cases.

On examination, diagnosis of penile fracture was straight forward in 11 patients with typical findings. One patient didn't have bleeding per urethra and was voiding, we found urethral injury intraoperatively.

The intraoperative findings are given in the following flow chart (Figure 5) and Table 3.

The postoperative course for all the six patients was uneventful. All the patients were discharged by postoperative day 2. The mean follow-up of patients was 24 months from the day of surgery. All patients voided well and were documented by uroflowmetry. All patients had no problems with erection. One patient developed penile curvature which did not affect his sexual health. Another patient developed stricture urethra. Two patients developed urinary tract infections (Table 4).

\section{Figure 5.}

Flow chart of intraoperative findingsrupture of the corpora and complete urethral transection.

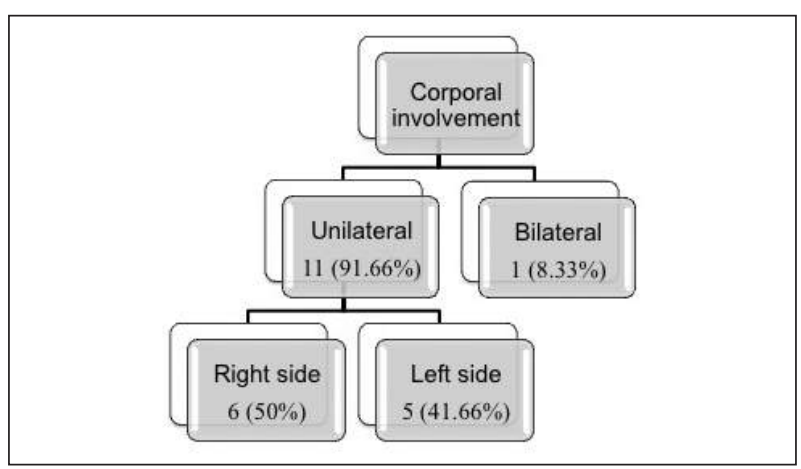

Table 4.

Complications.

\begin{tabular}{|lc|}
\hline Complications & Number of cases \\
\hline Penile curvature & $1(8.33 \%)$ \\
\hline Stricture urethra & $1(8.33 \%)$ \\
\hline Urinary tract infections & $2(16.66 \%)$ \\
\hline
\end{tabular}

\section{Discussion}

The literature shows an incidence of $10 \%$ to $38 \%$ of urethral injury overall (13). We observed $14.03 \%$ incidence in our case series of 75 patients. The frequency of urethral involvement was between 0 and 3 per cent in the Middle Eastern studies (10). The most common cause of penile fracture with urethral injury in our patients was vaginal intercourse with women on top position in 9 out of 12 patients (75\%). During intercourse with woman on top position, the angulation of erect penis makes its ventral surface vulnerable to collision with inferior margin of the pubic arch $\&$ symphysis pubis of the woman. In a phase of excitement or during a stage when they are unable to keep rhythm, the penis instead of penetrating deep into vagina, becomes entangled at the introitus and collides on its ventral surface with pubic arch of female partner. This phenomenon is exaggerated due to down- ward thrust of the woman or the upward stroke of man. Therefore, the urethra gets sandwiched between erect corpora of the man and pubic arch of the woman causing mucosal tear $\&$ bleeding per urethra (16). In our series of 75 patients, patients with urethral injury presented earlier compared to patients with only penile fracture, most likely because they were unable to void.

Diagnosis of urethral injury associated with penile fracture is based on history in patients if they had either difficulty voiding, retention of urine or bleeding per urethra. Urinalysis is not a mandatory component in the diagnosis of suspected urethral injuries, as it can confuse sometimes. In our study, 11 patients had macroscopic hematuria, whereas Gedik et al. reported the presence of microscopic hematuria in 6 out of 107 patients, but none of them had a urethral injury on exploration (17). So, presence of microscopic hematuria might not be an indication of urethral injury, so urinalysis test can be omitted. When in doubt retrograde urethrogram(RGU) is helpful in confirming the presence of a urethral injury but, it's not without false negative results. Mydlo and colleagues reported a false negative rate of $28.5 \%(2 / 7$ patients) in their small series (18), which might be due to overlying hematoma at the site of injury, which masks the defect. Hence the test is not recommended in routine practice. We did not perform any retrograde urethrogram in any of our patients, but we did adequate exposure of penis by circumferential sub coronal incision to prevent missing out urethral injury. Eleven patients presented with classical features with penile fracture with urethral injury, apart from one patient without bleeding per urethra, we were able to identify urethral injury intraoperatively which signifies the importance of proper degloving of penile skin for complete examination of injuries. All patients were subjected to emergency surgical exploration to prevent complications like urethral stricture, urethra-cavernous fistula and erectile dysfunction (14, 19-21). Complete rupture of urethra has been reported in literature (22), we got only one case (8.33\%) with complete rupture of urethra. Bilateral corporal injury occurs in 4-10\% of cases (23-24), we reported one case with an incidence of $8.33 \%$. Isolated urethral injury is very rare and might occur with absence of a snapping sound, sharp pain and detumescence (16). Most of our patients had partial urethral tears which account to 11 (91.66\%).

All patients had the site of the urethral trauma near the site of the corporal tear, which made it easy to identify the site of urethral injury. In one patient we weren't able to identify the location of urethral injury, so we took the help of saline mixed with methylene blue dye and introduction of a guide wire helped in the identification of urethral injury with more ease. Shaeer investigated the value of methylene blue in locating urethral tears in fracture penis and found it reliable and safe (25). Primary urethral anastomosis and corporal repair can be done after evacuation of hematoma and removing any devitalized tissue under cover of antibiotics. The outcomes of penile fracture with associated urethral injury repair are dependent on the timing of surgical exploration, the need for urethral catheterization, the type of incision and fashion of suture material utilized, and the requirement 
Table 5.

Comparison of different studies.

\begin{tabular}{|c|c|c|c|}
\hline Parameter & Our study & Derouiche et al. (28) & Attam et al. (27) \\
\hline No of patients & 12 & 10 & 8 \\
\hline Mean age & 31.5 years & 30 years & 30.4 years \\
\hline Age range & 25-36 years & 19-46 years & 23-51 years \\
\hline $\begin{array}{l}\text { Median time from the time } \\
\text { of injury to the time of presentation } \\
\text { to the hospital }\end{array}$ & 6 hours & 10 hours & $\begin{array}{c}\text { Mean duration } \\
\text { was } 2.7 \text { days, } \\
\text { median not assessed }\end{array}$ \\
\hline Crackling sound & $7(58.33 \%)$ & $10(100 \%)$ & $6(75 \%)$ \\
\hline Acute retention of urine & $3(25 \%)$ & $2(20 \%)$ & Not mentioned \\
\hline Bleeding per urethra & $11(91.66 \%)$ & $10(100 \%)$ & $6(75 \%)$ \\
\hline Aubergine sign/egg-plant deformity & $12(100 \%)$ & $10(100 \%)$ & $6(75 \%)$ \\
\hline Bladder palpable & $3(25 \%)$ & $2(20 \%)$ & Not mentioned \\
\hline Urethrogram & Not done & Not done & Not done \\
\hline Bilateral corporal involvement & $1(8.33 \%)$ & - & $1(12.5 \%)$ \\
\hline Unilateral corporal involvement & $11(91.66 \%)$ & $10(100 \%)$ & $7(87.5 \%)$ \\
\hline Right corporal involvement & $5(41.66 \%)$ & $6(60 \%)$ & $5(62.5 \%)$ \\
\hline Left corporal involvement & $6(50 \%)$ & $4(40 \%)$ & $2(25 \%)$ \\
\hline Proximal corpora & $6(50 \%)$ & $5(50 \%)$ & $6(75 \%)$ \\
\hline Mid corpora & $2(16.66 \%)$ & $4(40 \%)$ & Not mentioned \\
\hline Distal corpora & $4(33.33 \%)$ & $1(10 \%)$ & Not mentioned \\
\hline Median length of laceration & $28 \mathrm{~mm}$ & $24 \mathrm{~mm}$ & Not mentioned \\
\hline Partial urethral disruption & $11(91.66 \%)$ & $10(100 \%)$ & $7(87.5 \%)$ \\
\hline Complete urethral disruption & $1(8.33 \%)$ & - & $1(12.5 \%)$ \\
\hline Supra-pubic cystostomy tube & Not used & Used & Not used \\
\hline Penrose drain & Not used & Used & Not Used \\
\hline Medication to prevent erection & Estradiol & Diazepam & Estradiol \\
\hline $\begin{array}{l}\text { Median duration of transurethral } \\
\text { catheterization }\end{array}$ & 21 days & 13 days & 21 days \\
\hline Median hospital stay & 2 days & 14 days & 2 days \\
\hline Follow up mean & 24 months & 18 months & 34.3 months \\
\hline
\end{tabular}

\section{Conclusions}

Penile fracture is associated with urethral injury especially in the presence of suggestive history and physical examination like acute urinary retention or bleeding per urethra.

Immediate primary surgical management of both the penile fracture and urethral injury is a safe and effective option with minimal complications.

\section{Compliance with ethical standards}

The approval of ethical committee of our institution was taken before starting the study.

\section{Funding}

This study was not funded by anyone.

\section{REFERENCES}

1. McAninch JW, Santucci RA. Genitourinary trauma. In: Walsh P, Retik A, Vaughan E, Wein A, 2. editors. Campbell's urology. $8^{\text {th }} \mathrm{ed}$. Philadelphia: Saunders. 2002; p. 3707-44.

2. Maharaj D, Naraynsingh V. Fracture of the penis with urethral rupture. Injury. 1998; 29:483.

3. Hsu GL, Hsieh CH, Wen HS, et al. Penile venous anatomy: an additional description and its clinical implication. J Androl. 2003; 24:921-7.

for prophylactic antibiotics (18). With early repair, adequate exposure, complete hematoma evacuation, adequate rest to urethra for healing by catheterization can lead to favorable outcomes in the management of penile fracture associated with urethral injury. We used estradiol to prevent erections whereas Jallu et al. preferred using diazepam along with oxyphenbutzone (26).

We advised the patients to refrain from sexual activity for 6 weeks post-surgery but some studies showed sexual intercourse can be resumed 2 weeks after surgery (27-29).

Different follow-up protocols and strategies have been reported in different published series (28). In this study, the first follow-up was in the third week after the operation, and all patients underwent clinical evaluation. Later the patients were followed up at 3 months and 1 year with clinical examination, uroflowmetry and colour Doppler.

We noted penile curvature in one patient which didn't affect their sexual activity. One patient developed short segment stricture of the urethra which was managed with endoscopic dilatation.

Two patients developed urinary tract infections which were treated conservatively with antibiotics based on urine culture and sensitivity.

The limitation of our study is limited sample size. The Table 5 shows comparison between 2 similar studies.
4. Sawh SL, O'Leary MP, Ferreira MD, et al. Fractured penis: a review. Int J Impot Res. 2008; 20:366-9.

5. Zargooshi J. Sexual function and tunica albuginea wound healing following penile fracture: an 18 year follow-up study of 352 patients from Kermanshah. Iran J Sex Med. 2009; 6:1141-50.

6. Kalash SS, Young Jr JD. Fracture of penis: controversy of surgical versus conservative treatment. Urology. 1984; 24:21-4.

7. Eke N. Fracture of the penis. Br J Surg. 2002; 89:555-65.

8. Khinev A. Penile fracture. Khirurgiia (Sofiia) 2004; 60:32-41.

9. Chung CH, Szeto YK, Lai KK. 'Fracture' of the penis: a case series. Hong Kong Med J. 2006; 12:197-200.

10. Zargooshi J. Penile fracture in Kermanshah, Iran: the long-term results of surgical treatment. BJU Int. 2002; 89:890-4.

11. Klein FA, Smith MJ, Miller N. Penile fracture: diagnosis and management. J Trauma. 1985; 25:1090-2.

12. El-Taher AM, Aboul-Ella HA, Sayed MA, Gaafar AA. Management of penile fracture. J Trauma. 2004; 56:1138-40.

13. Sant GR. Rupture of the corpus cavernosum of the penis. Arch Surg. 1981; 116:1176-8.

14. Wespes E, Libert M, Simon J, Schulman CC. Fracture of the penis: conservative versus surgical treatment. Eur Urol. 1987; 13:166-8.

15. Seaman E, Santarosa R, Walton G. Immediate repair; key to managing the fractured penis. Contemp Urol. 1993; 5:13. 
16. Mohapatra TP. Kumar S. reverse coitus. Mechanism of urethral injury in male partner. J Urol. 1990; 144:1467-83.

17. Gedik A, Kayan D, Yamis S, et al. The diagnosis and treatment of penile fracture: our 19-year experience. Ulus Travma Acil Cerrahi Derg. 2011; 17:57-60.

18. Mydlo JH, Hayyeri M, Macchia RJ. Urethrography and cavernosography imaging in a small series of penile fractures: a comparison with surgical finding. Urology. 1998; 51:616-9.

19. Touiti D, Ameur A, Beddouch A, Oukheira H. La rupture de l'urethre au cours des fractures de la verge. A propos de 2 observations. Prog Urol. 2000; 10:465-468.

20. Biserte J, Nivet J. Traumatisme de l'urethre anterieur: diagnosticet traitement. Ann Urol. 2006; 40:220-232.

21. Paparel P, Ruffion A. Rupture des corps caverneux: aspects techniques de la prise en charge. Ann Urol. 2006; 40:267-272.

22. Heng CT, Brooks AJ. Penile fracture with complete urethral rupture. Asian J Surg. 2003; 26:126-7.
23. Mydlo JH Surgeon experience with penile fracture. J Urol. 2001; 166:526-528.

24. Koifman $L$, et al. Penile fracture experience in 56 cases. Int Braz J Urol. 2003; 29:35-39.

25. Shaeer O. Methylene blue-guided repair of fractured penis. J Sex Med. 2006; 3:349-54. http://dx.doi.org/10.1111/j.1743-6109. 2005.00155.x

26. Jallu A, Wani NA, Rashid PA. Fracture of the penis. J Urol. 1980; 123:285-286.

27. Masarani M, Dinneen M. Penile fracture: diagnosis and management. Trends in Urology Gynaecology \& Sexual Health. 2007; 12:20-24.

28. Derouiche A, Belhaj K, Hentati H, et al. Management of penile fractures complicated by urethral rupture. Int J Impot Res. 2008; 20:111-114.

29. Amit A, Arun K, Bharat B, et al. Penile fracture and associated urethral injury: experience at a tertiary care hospital. Can Urol Assoc J. 2013; 7:E168-E170.

\section{Correspondence}

Priyatham Kasaraneni, MD

kasaraneni.priyatham@gmail.com; kpriyatham@yahoo.co.in

Prasad Mylarappa, MD

prasadmyluro2@gmail.com

Ramesh Desi Gowda, MD

arunacr1@gmail.com

Sandeep Puvvada, MD

dr.sandeep001@gmail.com

Dheeraj Kasaraneni, MD

dheerajkasaraneni@gmail.com

Department of Urology MS Ramaiah Medical College, Bengaluru, India 